\title{
A eticidade na pesquisa qualitativa em saúde: o dito e o não dito nas produções científicas
}

\author{
The ethics of qualitative research in health: \\ the said and the unsaid in the scientific production
}

Flávia Regina Souza Ramos ${ }^{1}$

$M$ irelleFinkler ${ }^{2}$

Evelise Ribeiro Gonçalves ${ }^{2}$

João Carlos Caetano ${ }^{3}$

${ }^{1}$ Departamento de Enfermagem, Centro de Ciências da Saúde, UniversidadeFederal de Santa Catarina. Campus Universitário Trindade 88040-970 Florianopolis SC. flaviar@ccs.ufsc.br ${ }^{2}$ Secretaria M unicipal de Saúde, Prefeitura M unicipal deFlorianópolis.

${ }^{3}$ Departamento deSaúde Pública, Centro de Ciências daSaúde, Universidade Federal deSanta Catarina.
Abstract This study investigated the ethics of qualitative research by using bibliographic research. Data were collected in scientific articles from a Brazilian journal of collective health and the access to the sources was electronic. It were analyzed 117 articles of qualitative research which corresponded to $23.49 \%$ of the total production of the journal from 01/1998 to 03/2007. The information collected was organized considering the identification, themes/object, theoretical referential, methodology and ethical aspects involved. The analysis proposed a discussion based on what the researchers express about ethics on their qualitative studies when it comes to two different kinds of relation: between the researchers and their research-subject and with their co-workers. The conclusions brought up many issues to be discussed on the daily routine of the research activity and that demands exposition and openness to criticism. There is also an urge to think what the "said" and the "unsaid" can reveal underneath the obedience to the rules, launching to the process of maturing and to the theoretical consistence of the researchers, especially in the ethical dimension of the researching activity. A huge part of those challenges are of direct responsibility of the institutions which are in charge of the re searcher's formation.

Key words Ethics, Research, Qualitati veresearch
Resumo Esta pesquisa bibliográfica analisou o tema da eticidade em pesquisa qualitativa. Os dados foram coletados em artigos científicos de uma revista brasileira de saúde coletiva de acesso eletrônico. Foram analisados 117 artigos, correspondentes às pesquisas qualitativas e a $23,49 \%$ das publicações entre 01/1998 a 03/2007. 0 corpo dedados foi organizado em torno de questões referentes à identificação, à temática/objeto, ao referencial teórico, à metodologia e aos aspectos éticos envolvidos. A análise propôs questões e indicou relevâncias a partir do que os pesquisadores expressam acerca da ética em seus relatos de pesquisa qualitativa, referentemente a dois tipos de relações- do pesquisador com o "sujeito pesquisado" e com "seus pares". Concluiu-seque há muito a ser problematizado acerca do cotidiano da pesquisa, o que exige exposição e abertura à crítica. É preciso conhecer o próprio discurso sobre o tema e pensar no que "o dito" e o "não dito" podem revelar sob o aparente resguardo da obediência às normas, reconhecen do que os desafios para a qualificação remetem ao amadurecimento eà consistência teórica deseusinvestigadores, especialmente no que se refere à dimensão ética do ofício de pesquisar. Grande parte de tais desafios incidem diretamente sobre as instituições que assumem a responsabilidade na formação de pesqui sadores. Palavras-chave Ética, Ética em pesquisa, Pesquisa qualitativa 
Pensando a ética em pesquisa: o objeto de estudo e sua abordagem metodológica

Quando deslocamos a aten ção dos locais e focos nos quais se mostram de modo mais evidente as questões éticas da pesquisa, podemos montar e desmontar outras referências para pensar este tipo de questão. Dito de outro modo, sob novas "atenções", é possível buscar e pensar além do "onde" e do "como" pensávamos encontrar e nomear nossas questões éticas. 0 próprio sentido e os limites que costumam estabelecer o que se diz e o que se deve dizer ao falar em ética na investigação passam a ser alvo de nossa problematização. Assim, podemos deslocar, senão toda a atenção, ao menos o foco exclusivo sobre temas como o consentimento informado ou os comitês de ética, para pensarmos também "como a ética em pesquisa se torna um problema, não apenas digno de ser pensado, mas possível de ser pensado, por investigadores do campo da saúde?" ou "como se tornou quase impraticável hoje fazer pesquisa em saúde sem fazer referência a certos protocolos e requisitos nomeados como éticos?" A queconjunto mais amplo dediscursos e práticas se vincula este novo tipo de exigência para a prática investigativa ${ }^{1}$ ?

Obviamente que perguntas como estas, inspiradas em autores como Foucault ${ }^{2}$ e $\mathrm{H}_{\text {acking }}{ }^{3}$, já demonstram uma filiação teórica capaz de permitir este movimento crítico - ou de crítica da crítica, se assim considerarmos a intenção detornar problemático nossas próprias problematizações, além da intenção de sabermos o queestamos fazendo e dizendo quando pensamos estar fazendo a "boa pesquisa", seguindo o protocolo politicamentee eticamente correto, nos protegendo dos riscos da má conduta, da impostura e da ignorância. Por que parece tão útil einegável demonstrar "que se sabe" e"se compartilha" princípios, pautas e normas por meio das quais se julga a prática de investigar?

Sobre a evolução da pesquisa com seres humanos no Brasil, cabe fazermos algumas considerações sobre as transformações das práticas de investigação mobilizadas desde a Resolução do Conselho Nacional de Saúde (CNS) nº 196/96 ecomplementares. Estas visam proteger os sujeitos de pesquisa e contribuir com a qualidade das pesquisas que "queiram ser cientificamentefidedignas, metodologicamente corretas, moralmente aceitáveis e socialmente relevantes"4. Fundamentada nos principais documentos internacionais que emanaram declarações e diretrizes sobre pesquisas com seres humanos, na legislação brasileira eno referencial teórico da bioética principialista, a Resolução n 196/96 trata desde conceitos relacionados à pesquisa com seres humanos, tais como "riscos da pesquisa”, "vulnerabilidade" e "incapacidade", até as implicações da eticidade nas pesquisas, passando pelas exigências relacionadas ao consentimento livre esclarecido, as considerações sobre riscos e benefícios, o formato do protocolo de pesquisa e a criação/operacionalização de Comitês de Ética em Pesquisa (CEP) e da Comissão Nacional de Ética em Pesquisa (CONEP) ${ }^{5}$.

A CONEP é uma das comissões do CNS que tem como função implementar normas e diretrizes regulamentadoras de pesquisas envolvendo seres humanos. Ademais, possui função consultiva, deliberativa e educativa, e atua coordenando uma rede de CEP, com os quais forma 0 Sistema CEP-CONEP5,6. Aos CEP, organizados nas instituições que realizam pesquisas, cabe a revisão de todos os protocolos de pesquisa envolvendo seres humanos, de modo a garantir e resguardar a integridade e os direitos dos voluntários participantes nos estudos, em nome da sociedade edeforma independente, qualificando eticamente os projetos. Tornam-se, assim, corresponsáveis pela parte ética, juntamente com pesquisadores, instituições epatrocinadores. Possuem também função consultiva e educativa, fomentando a reflexão em torno da ética na ciência, além da atribuição de receber denúncias e requerer a sua apuração $0^{5,6}$. Já a CON EP avalia os aspectos éticos de pesquisas em áreas temáticas especiais - escolhidas por critério de risco e por abarcar dilemas éticos mais complexos, tais como genética ereprodução humana, populações indígenas, pesquisas multicêntricas, estudos que envolvam biossegurança, após análise e aprovação prévia pelos CEP institucionais. Funciona também como um órgão de controle social das pesquisas realizadas no país, bem como uma instância de recursos e assessoria ao M inistério da Saúde, ao CN S e ao SUS $5^{5,6}$.

A publicação da Resolução n ${ }^{196}$, em outubro de 1996, estimulou e orientou a criação dos primeiros CEP no decorrer do ano seguinte a sua publicação. Com base nos registros da $\mathrm{CO}$ NEP7 ${ }^{7}$, pudemos calcular que 82 CEP foram criados e aprovados em 1997. N os anos seguintes, 0 número de CEP continuou crescendo, mas foi a partir de 2003 que esse aumento se tornou mais significativo, resultando atual menteem um total de 527 CEP (Tabela 1).

Dificilmentese poderia pensar o tema da ética em pesquisa sem referência a este processo políti- 
Tabela 1. Total deCEPs criados/aprovados por ano.

\begin{tabular}{lc}
\hline Ano & CEPs criados/ aprovados* \\
\hline$(2007)$ & -- \\
2006 & $66-12,52 \%$ \\
2005 & $73-13,85 \%$ \\
2004 & $65-12,33 \%$ \\
2003 & $53-10,05 \%$ \\
2002 & $38-7,21 \%$ \\
2001 & $38-7,21 \%$ \\
2000 & $34-6,45 \%$ \\
1999 & $36-6,83 \%$ \\
1998 & $42-7,96 \%$ \\
1997 & $82-15,55 \%$ \\
Total & 527 \\
\hline
\end{tabular}

* Fonte: Brasil (2006).

co normativo que participa da definição de uma dada "eticidade". Uma eticidade identificada nos trechos obrigatórios de uma pesquisa qualitativa é aquela que diz o que deve ser dito; "dito" que qualifica e dá permissão para que tudo o que se quer dizer (sobre o objeto de estudo, sobre os resultados) o possa ser sem perder credibilidade. "Outras coisas ditas" se referem à relação do pesquisador com seus sujeitos informantes (coleta de dados) e com seus pares - especialmente com um dispositivo de certificação legitimado pelos pares que preten de assegurar que o "achado científico" não seja perdido/desmerecido por "incorreções" do processo de pesquisa. Este possível e tão indesejável desvalor, risco ou incorreção éeliminado ou atenuado quando se julga que um projeto de pesquisa passou pelo crivo capaz de fazer a vigilância ética sobre o processo de pesquisa. Como se toda a questão da ética em pesquisa pudesse estar contida nesta relação, como se os únicos problemas a serem enfrentados fossem para elaborar boas normas, divulgá-las suficientemente, constituir um consenso mínimo em torno delas, possuir bons experts para avaliar sua aplicação e contar com diferentes acessórios ( $r$ gulamentares, classificatórios, de vantagens/mé ritos e perdas/punições) para que tal dispositivo funcione adequadamente, garantindo que nenhum pesquisador desejeficar fora dele. Ora, esta é apenas a porção mais obrigatória, normativa e, portanto, a mais "dita" de nossas falas sobre eticidadeem pesquisa. A pesar disto, não podeser desvalorizada a consideração de tais aportes como indícios de uma "transição paradigmática” na per- cepção social das práticas de pesquisa, já que implica a "prestação de contas" aos sujeitos pesquisados e à sociedade como um todo ${ }^{4} \mathrm{e}$, como no caso da atuação dos CEP, de uma demanda social que implica conhecimentos e atitudes interdisciplinares, intencionalidade educativa e compromisso com o bem-estar social ${ }^{8}$.

Se os aspectos que se referem à legitimidade destes comitês são discutidos como importantes - daí as orientações para sua composição e atuação - não podem ser esquecidas as condições de infraestrutura, deinstrumentos de trabal ho, avaliação e evolução ${ }^{9}$, além das condições de formação adequada dos membros dos CEP para as competências necessárias ou de evidências/relatos sobre a insuficiente atuação educativa de CEP, dentre outras dificuldades de implantação práti$\mathrm{ca}^{10}$. Isto alerta sobre apenas alguns dos limites concretos para uma qualidade ecredibilidade do trabalho dos CEP mais genéricas e ampliadas (já que não se pode pensar em homogeneidade) face às discrepâncias de condições e experiências institucionaiseindividuais.

\section{M etodologia}

Este estudo teve como objetivo analisar o tema da "eticidade" em pesquisa qualitativa em saúde a partir do que se pode apreender (pistas) sobre a prática investigativa em artigos científicos de um conceituado periódico da área da saúdecoletiva, no caso, a revista Ciência e Saúde Coletiva. $\mathrm{N}$ ão chegamos a caracterizar este estudo como um compromisso com um "modo pós-estruturalista" de investigar - o que exigiria mais intensos investimentos analíticos - mas não podemos deixar de marcar tal inspiração ou movimento de aproximação com o modo pós-estruturalista de tornar um tema um problema ou saber por que certos problemas nos dizem respeito. Deste modo, o próprio objetivo da análise se torna propor questões, indicar relevâncias e fazer novas perguntas sobre o que nós pesquisadores consideramos importante acerca da ética em pesquisa qualitativa em saúde.

Alguns flashes de nossa prática de pesquisa podem ser exemplares para um tipo de exercício problematizador e os produtos desta prática na forma de artigos científicos - podem ser o material empírico a partir do qual tais flashes ou pistas são remontados. Ao assumir a perspectiva problematizadora foucaultiana, entende-se, com este autor, que problematização não quer dizer representação deuma objeto preexistente, nem 
tampouco a criação pelo discurso de um objeto que não existe. É o conjunto das práticas discursivas ou não discursivas que faz alguma coisa entrar no jogo do verdadeiro e do falso e o constitui como objeto para o pensamento (seja sob a forma da reflexão moral, do conhecimento científico, da análise política, etc.) $)^{11}$.

Assim, a perspectiva crítica pós-estruturalista a que se filia esta reflexão, longe de definir métodos e procedimentos precisos, busca articular reflexão, argumentação e interpretação ao problematizar um saber-poder (como o dedizer o queé ético em pesquisa) em sua emergência e em alguns de seus desdobramentos e manifestações. Assim, o objeto torna-se o próprio discurso ou práticas discursivas, pois em toda sociedade a produção do discurso é ao mesmo tempo controlada, selecionada, organizada e redistribuída por certo número de procedi mentos que têm por função conjurar seus poderes e perigos, dominar seu acontecimento aleatório, esquivar sua pesada e terrível materialidade 2 . Focar-se sobre discurso impõe pensar no conjunto de práticas e modos como 0 saber é aplicado, valorizado, distribuído e atribuído na sociedade, ou seja, seus modos de funcionamento. Em sua funcionalidade é que o objeto desta reflexão, a eticidade em pesquisa qualitativa, podeser inicialmenteexplorado, especialmente por que, nesta perspectiva problematizadora, é de fundamental importância imaginar outros modos de olhar para qualquer coisa que se apresente carregada de autoridade e unidade.

Foi desenvolvida uma pesquisa documental, tendo como fonte de dados artigos científicos da revista Ciência eSaúdeColetiva. 0 acesso àsfontes se deu por meio eletrônico, a partir do período em que o periódico passou a disponibilizar artigos na íntegra por esta via. Inicial mente, realizamos um levantamento do número de artigos temáticos e de temas livres publicados no período dejaneiro de 1998 a março de 2007, adotando como critério de inclusão o fato de ser pesquisa e, subsequentemente, de ser pesquisa qualitativa ou quantitativo-qualitativa. Chegamos então a um total de 117 artigos, correspondentes a 23,49\% da produção científica da revista no período. Os artigos foram lidose analisados na íntegra e, após uma primeira etapa da análise, foi elaborado um quadro síntese com categorias eleitas como essenciais para o prosseguimento da análise, privilegiando dados de identificação (ano, volume, instituição), temática/objeto, referencial teórico, metodologia, aspectos éticos (TCLE, CEP e outros achados). 0 cotejamento e análise apro- fundada destes achados organizados produziram as sínteses e reflexões aqui focalizadas. Para fins de identificação das fontes, são apresentados dados de localização dos artigos (Tabela 2). Devido ao caráter público das fontes, este tipo de estudo não requer submissão a um CEP, mas salienta-se que seus autores não possuem nenhum conflito de interesses.

A eticidadeem pesquisa qual itativa: o dito e o não dito em artigos científicos (resultados)

Retomando os aspectos levantados sobre a evolução da pesquisa com seres humanos e da pesquisa qualitativa no Brasil, os resultados desta pesquisa parecem ressaltar a relação entre os procedimentos operacionais e os discursos normativos e legais sobre esta prática. Ao compararmos o total de artigos publicados que relataram ter submetido seus projetos de pesquisa a CEP, observarmos um início recente (desde 2003), com um incremento paralelo ao de criação destes comitês, que se tornou mais frequente nos últimos dois anos (Tabela 3). Tais achados nos levam a pensar que o funcionamento de um maior número de CEP institucionais e, consequentemente, uma maior facilidade (ou exigência) em acessá-los para submeter projetos, seja um fator importante na submissão de pesquisas à aprovação ética. O utras possíveis justificativas seriam o aumento recente e gradual, tanto no número de pesquisas em ciências sociais na saúde, como no número de publicações (Tabela 3); a exigência de documentação comprobatória de aprovação do projeto por CEP e/ou CONEP por parte das agências financiadoras e dos corpos editoriais das revistas científicas; ou ainda, uma crescente conscientização dos pesquisadores com relação à necessidade de submeter seus projetos de pesquisas a CEP, sejam eles da área biomédica ou das ciências sociais em saúde. Isto porquetoda a prática de pesquisa que envolve seres humanos (pesquisadores e pesquisados) tem uma dimensão ética à medida que implica, direta ou indiretamente, a relação entre sujeitos morais (ou que assim deveriam ser considerados), de modo que conflitos de interesses e de valores possam estar presentes. A avaliação dos CEP, então, tem a dupla função de descrever/compreender a moralidade das pesquisas e de resolver/regular os conflitos no sentido de propor a melhor solução possível ou a máxima redução de eventuais danos, inclusive os do tipo moral ${ }^{4}$. 
Tabela 2. Identificação das fontes documentais (artigos estudados) por ano de publicação, volume, número e página inicial dos artigos.

\begin{tabular}{|c|c|c|}
\hline Ano & Vol./Num. & Página inicial dos artigos \\
\hline 2007 & v.12, n.1 & p.39; р. 105; р. 221; р. 231; p.239; p.263 \\
\hline \multirow[t]{4}{*}{2006} & v.11, n.1 & р.45; р.53; р.63; р.71; р.89; р. $115 ;$ р.155; р.161; р.191; р.211; р.219 \\
\hline & v.11, n.2 & p.385; p.397; p.429; p.473; p.483 \\
\hline & v. $11, n .3$ & p.621; р.765; р.775; р.785; р.797; p.817; p.827 \\
\hline & v.11, n.4 & p.1055; p.1413; \\
\hline \multirow[t]{5}{*}{2005} & v.10, n.1 & p.35; p. 151; p.111; p.191; p.245 \\
\hline & v.10, n.2 & р.315; р.323; р.333; р.347; р.357; р.381; р.399; р.463; р.473; р.399 \\
\hline & v. $10, n .3$ & p.615; р.627; p.639; p.669; p.677; р.729; р.739; р.757; p.771 \\
\hline & v.10, n.4 & p.929; p.939; p.1015; p.1047; p.1055; p.1063; p.905 \\
\hline & v.10, supl. & p.49; p.111; supl., p.133; p.179; p.221; p.255; p.267 \\
\hline \multirow[t]{4}{*}{2004} & v9, n1 & p.43; р. 113; р. 139; p.147; р. 213; p.225; p.191 \\
\hline & $v 9, \mathrm{n} 2$ & p. 411; p.493; \\
\hline & v9, n3 & p.643; р.655; p.679; p.711 v9, n3, p.751; \\
\hline & v9, n4 & p.1013; p.1023; p.1057 \\
\hline \multirow[t]{3}{*}{2003} & v8, n1 & p.275 \\
\hline & v8, n2 & p.621; p.611; p.599 \\
\hline & v8, n4 & p.973; p.1047; p.1057 \\
\hline \multirow[t]{2}{*}{2002} & $\mathrm{v} 7, \mathrm{n} 2$ & p.243; p.275; p.363 \\
\hline & v7, n4 & p.907; p.925 \\
\hline 2001 & v6, n1 & p. $43 ;$ p. $87 ;$ p. $105 ;$ p.115; p.125; p.152 \\
\hline 2000 & v5, n1 & p.39; p.193 - i \\
\hline 1999 & v4, n1 & p.53; p.81; p.131; p.161 \\
\hline 1998 & v3, n2 & p.125; p. 143 \\
\hline
\end{tabular}

Tabela 3. Total de artigos publicados na revista, total de pesquisas qualitativas e/ou quantitativas-qualitativas e de artigos que relataram pesquisas aprovadas por CEP, por ano.

\begin{tabular}{lrrr}
\hline \multicolumn{1}{c}{ Ano } & Artigos publicados & Pesquisas quali e/ou quanti-quali & Pesquisas aprovadas por CEP \\
\hline$(2007)$ & $(22)$ & $(6)$ & $(3)-(50 \%)$ \\
2006 & 80 & $25-31,25 \%$ & $12-48 \%$ \\
2005 & 108 & $39-36,11 \%$ & $10-25,64 \%$ \\
2004 & 76 & $18-23,68 \%$ & $2-11,11 \%$ \\
2003 & 68 & $10-14,7 \%$ & $1-10 \%$ \\
2002 & 58 & $5-8,6 \%$ & 0 \\
2001 & 30 & $6-20 \%$ & 0 \\
2000 & 24 & $2-8,3 \%$ & 0 \\
1999 & 22 & $4-18 \%$ & 0 \\
1998 & 10 & $2-20 \%$ & $25-21,36 \%$ \\
Total & $498-100$ & $117-23,49 \%$ & \\
\hline
\end{tabular}

Observou-se também uma evolução ao longo dos anos na produção de pesquisas qualitativas e quantitativo-qualitativas, proporcional ao número de artigos publicados. Enquanto no ano 2000 essa produção correspondia a apenas 8,3\% da produção da revista, em 2005, essa proporção estava em 36,11\% e, em 2006, em 31,25\% (Tabela 3).

Em relação às instituições que publicaram artigos no período analisado, temos um total de 
44 (para facilitar a análise, consideramos sempre a instituição do primeiro autor do artigo), sendo que, destas, 24 eram públicas $(54,55 \%)$ e vinte, privadas $(45,45 \%)$. Também do total de instituições, temos 43,18\% pertencentes à Região Sudeste, $25,97 \%$, à Região Sul, $20,45 \%$, à Região Nordeste, $6,81 \%$, à Região Centro-O estee 4,54\% provenientes de outros países, não havendo nenhuma pesquisa qualitativa ou quanti-qualitativa oriunda de instituições da Região Norte. Este dado condiz com a situação brasileira de concentração e distribuição regional desigual deinstituições de ensino e de pesquisa, assim como de pesquisadores, relacionadas a também diferentes concentrações populacionais, além de históricas questões políticas e econômicas com impacto sobre a educação, a ciência e a tecnologia.

Já quanto ao que se pretendeu neste estudo, em termos deidentificação de uma eticidade "dita", os artigos selecionados mostraram que esta se foca, principalmente, em referências às diretrizes da Resolução CN Sn ${ }^{\circ}$ 196/96 eaos princípios bioéticos. Nos artigos, são referidos cuidados tomados em relação aos sujeitos de pesquisa, antes e durantea coleta de dados, traduzidos em respeito ao anonimato dos entrevistados e/ou codificação dos nomes dos sujeitos de pesquisa (28 de 117 estudos), explicitação do uso do termo de consentimento livre e esclarecido (TCLE) (24); referência à gravação de entrevistas com o consentimento do sujeito de pesquisa (9); menção a sujeitos de pesquisa voluntários (8); esclarecimento dos participantes sobre os objetivos e a metodologia da pesquisa (8); comprometimento com 0 sigilo absoluto (5). Outros aspectos foram também relatados, mas com frequências ainda menores: respeito à privacidade do sujeito de pesquisa (2); preocupação com a autonomia (1); explicitação do direito de recusa (1); proteção da imagem (1); confidencialidadedos dados (1); garantia de não estigmatização (1); garantia da não utilização das informações coletadas para prejudicar pessoas e/ou a comunidade (1); ressarcimento dos sujeitos de pesquisa pelos gastos com transporte (1); preocupações com o constrangimento frenteà abordagem de "temas tabus" (1) e frente às anotações no diário de campo, deixando-as apenas para depois da entrevista (1). Chama-nos a atenção, no entanto, a baixa frequência com que tais cuidados éticos são relatados, uma vez que os estudos de abordagem qualitativa requerem significativa aproximação entreo pesquisador e o pesquisado e a confiança é um aspecto importante para a garantia da qualidade dos dados e da pesquisa como um todo ${ }^{12}$.
Identificamos outros tipos de cuidados para com os sujeitos, na fase "pós-coleta de dados", entre os quais a preocupação com a capacitação da comunidade a partir dos dados coletados (1); a socialização/devolução dos resultados/achados (2); a reflexão coletiva sobre os resultados, encaminhando sugestões de soluções para problemas encontrados (2) e o comprometimento com os sujeitos de pesquisa através do fornecimento de medicamentos para os doentes e de vaci nas atrasadas (1).

Em relação a estes cuidados éticos relatados, podemos interpretar que a maior referência ao anonimato e ao uso de termo de consentimento livre e esclarecido relaciona-se ao fato de estas serem exigências já postas tanto em termos de uma dada cultura acadêmica quanto de requisitos formais para a circulação da informação científica; já os outros tantos cuidados passam a ser explicitados conforme o que cada pesquisador julga pertinente e necessário destacar. É claro que pequenas e grandes decisões do pesquisador estão implicadas em toda a trajetória da investigação, mas aqui cabe reconhecer que pouco sabemos sobre o conteúdo e as condições de formulação do que parece ser a pauta do pesquisador quando decide o queé ou não é relevante relatar sobre o processo de pesquisa que desenvolve, enfim, "como decide o que precisa ser dito". A partir daí, acessamos não apenas o que poderia ser reconhecido, após análises mais aprofundadas, como lacunas da formação do pesquisador ou dos mecanismos reguladores da prática científica mas, apenas e especialmente, as formas como problematizamos nossas próprias práticas, pondo em funcionamento linguagens e valores a partir dos quais é possível demarcar este fazer investigativo em suas visibilidades e invisibilidades.

Além da eticidaderelativa ao que "deveser dito", encontramos al guns outros cuidados éticos acerca dos métodos de pesquisa, tais como a realização de pré-testes (6); a preocupação com a fidedignidade dos dados perante o relato de transcrições com o preenchimento dos diários de campo de forma imediata às coletas e 0 treinamento de entrevistadores (3). Outros cuidados éticos também observados foram aqueles dirigidos aos pares, como a apresentação das perguntas realizadas em entrevistas (3) e a explicitação dos procedimentos quando da saída do campo (3). A utilização da linguagem ethic, ou seja, a preservação das expressões originais utilizadas pelos sujeitos de pesquisa (evidenciada em 47 artigos), também pode ser relacionada a uma preocupação tanto com os sujeitos pesquisados quanto com os pa- 
res e leitores, embora não possa ser considerada como um critério ou condição ética, uma vez que a ausência de tal opção não indica uma deficiência, podendo significar o contrário, em muitas situações.

A ética no fazer cotidiano do investigador pode se desdobrar em dois tipos de relações - do pesquisador com o outro como "sujeito pesquisado" e com o outro como "seus pares". Em cada uma destas relações, parte-se do reconhecimento da alteridade, situando o pesquisador em seu local, interesse e situação, enfim um lugar diferenciado no qual se assume como capaz de enunciar saberes por meio de "modos de endereçamento" de terminados por uma idéia sobre "quem um endereçamento pensa que o seu público é". Os textos científicos também são endereçados e os modos pelos quais um texto é elaborado, sob certas regras de produção e circulação, demarcam as possibilidades de diálogo em círculos mais ou menos amplos, mais ou menos esotéricos, que conformam os campos de conhecimentos ${ }^{8}$. Ora, também sob este foco, podemos pensar nossos informes científicos, considerando que o que decidimos dizer sobre as questões éticas da pesquisa indicam não apenas um entendimento sobre ética, mas também o que pensamos sobre quem é 0 nosso leitor, "o que el e deve saber" e como.

Foi expressivo o número de artigos (30) que em nenhum momento relatou, implícita ou explicitamente, preocupaçõeséticas. Isto poderia ser considerado conflitante com outro pressuposto relativamente aceito, que justifica a importância dos pesquisadores (em abordagens qualitativas) relatarem os incidentes e as questões éticas encontradas em seus estudos para garantir os avanços das discussões e análises éticas e a prevenção de erros futuros ${ }^{12}$. Entretanto, o tipo de material estudado não é suficiente para afirmar que a ausência de relato de aspectos éticos seja indicativa de que cuidados e procedimentos éticos não tenham sido tomados pelo pesquisador (como consentimento, por exemplo), apenas que não foram relatados. Também existem diversas possibilidades a serem supostas, como a de pesquisadores justificarem ao CEP a não obtenção de TCLE (seria necessário relatar tal fato?) Ou seja, tanto a ausência como a insuficiência deste tipo de informações não pode ser usada como base para uma crítica do processo de pesquisa, mas apenas levantar pontos de reflexão sobre o que, como e porque dizemos o que dizemos em nossos artigos. Estas ausências também podem estar relacionadas, conforme já apontado, ao período de criação e atuação dos CEP, que passaram a ter uma atuação mais ampliada somente muito recentemente e, da mesma forma, é atual a exigência de tal submissão por parte dos periódicos, 0 que não atingiria os artigos mais antigos (podemos supor que o que não foi explicitado nos artigos mais recentes foi verificado e exigido pelo periódico?). Outro limitante destetipo de conclusão sobre a eticidade do processo de pesquisa se refere a especificidade de abordagens qualitativas (como construtivistas ou participantes, por exemplo) quepartem do suposto inicial da plena compreensão eenvolvimento dos sujeitos no estudo e que, portanto, certas descrições e informações estariam "subentendidas" como inerentes ao desenho metodológico.

Além disso, as relações entre pesquisador e pesquisado em estudos qual itativos nem sempre constituem aspectos abordados pelas normas regulamentadoras sobre ética em pesquisa com seres humanos. Inclusive, lidar com esse tipo de relação, tão próxima e baseada na confiança entre os envolvidos, coloca questões éticas diferentes daquelas de pesquisas que pressupõem um pesquisador neutro, objetivo, que busca distância e o não envolvimento com o pesquisado ${ }^{13}$. Dessa forma, há argumentos que defendem que a natureza do relacionamento entre pesquisador e sujeito, bem como os cuidados éticos inerentes a essa relação em pesquisas qualitativas, deveriam ser contempladas nas diretrizes sobre ética em pesquisa ${ }^{12}$. Ao mesmo tempo, poderíamos questionar sobre a possibilidade de normativas serem exaustivas ao ponto de detalhar e abranger todas as sutilezas e situações, previstas ou não, do processo de pesquisa e relações entre os sujeitos, suficientes a ponto de prescindirmos do bom senso na condução dos processos e nos efeitos de seus resultados, incluindo aqui noções como de responsabilidade e solidariedade ${ }^{14}$.

M esmo sendo o uso do TCLE um dos aspectos mais referenciados, este também pode ser considerado limitado (apenas 24 publicações num total de 117) se considerada sua importância presumida e o fato de personificar, como antes mencionado, o papel eticamenteexigido dentro das coisas que "devem ser ditas". Perguntamo-nos então o que significaria esse "não dito", uma vez que tudo o que escapa destes referentes permaneceno grandeconjunto do subentendido e do genérico. No entanto, as escolhas sobre 0 que dizer marcam o não dito e, portanto, 0 "não dito" também "diz muito", inclusive sobre possibilidades de sua enunciação. 0 que não é dito sobre a eticidade de nossas pesquisas pode ser problematizado a partir de outras tantas coisas 
ditas, não constituídas como "coisas da ética". Então, cabe perguntar sobre que pistas nos são dadas no interior destas outras coisas ditas (que não da ética).

Nossos temas, nossas palavras-chave nos dizem de escol has, compromissos e visões possíveis sobre a realidade. Uma aproximação à relação entre ética e pesqui sa qualitativa em saúdese dá pela simples consideração destas escolhas temáticas. Do conjunto de artigos pesquisados, sobressaem, dentre outros, dois grandes eixos temáticos: (1) que articula temas da promoção da saúde e políticas públicas e abarca uma série de conceitos, práticas edemandas, como da educação em saúde, qualidade de vida, participação e controle social, cidades saudáveis, entre outros (22 estudos) e (2) que articula temas do processo detrabalho em saúde, seja sobreum foco mais profissional (enfermagem, odontologia), um foco na relação entre o trabal ho concreto e modelos assistenciais do SUS (PSF) ou um foco na saúde do trabalhador, aí incluindo desde qualidade de vida, acidentes até a relação saúde/ambiente/trabalho (21). Outros eixos se referem a: (3) saúde mental e atenção psicossocial (representações, avaliação de serviços, drogas, entre outros) (11); (4) ética ebioética, gênero e sexualidade, corpo, religiosidade (assim agrupados por tomarem objetos socioculturais complexos em suas interfaces com a saúde e com populações específicas, como adolescentes) (10); (5) violência sob diferentes perspectivas; (6) saúde bucal e prática odontológica (8); (7) humanização, hospitalização, parto humanizado (8) 8) Formação profissional, racionalidades, identidades e relações (7); (9) temáticas com especificidades diversas, como relação saúde e mídia (4), HIV/aids e outros enfermidades, terapêuticas ou conhecimentos em saúde (12).

Qualquer classificação temática será flexível, pois um modo de categorizar indica uma sensibilidade construída em um campo de conhecimentos, ou seja, uma capacidade de perceber e destacar relevâncias mais ou menos compartiIhadas por um conjunto de sujeitos que formam este campo, ou vistas como pertinentes por este conjunto. Assim, poderíamos perguntar sobre as condições que permitem que estes temas e objetos (e não outros) tornem-se problemáticos e interessantes a um campo de saber. Ou seja, por que estes temas são interessantes e que tipo de reflexão ética está implicada nestas condições e eleições. Enfim, trata-se de destacar os efeitos "éticos" de escolhas que, por outros ângulos, pareceriam apenas decisões técnicas.
Numa síntese preliminar, já se antevê uma intimidade entre o ético e o político - a forma como, a partir de um considerável acervo de pesquisas qualitativas em saúde, este tipo de abordagem mostra compromissos latentes e expressivos com processos históricos de transformação que atingem nossa cultura, nossas concepções e "soluções" sobre o processo de viver, adoecer, sofrer e morrer. Enfim, abordagens qualitativas que confirmam a superação do mito da neutralidade e assumem a investi gação como tarefapolítica.

Pesquisas como essas devem ser realizadas prioritariamente em nome de sua relevância social enão apenas em função de mal efícios ebenefícios para os sujeitos da pesquiså. A sociedade deve ser examinada e pesquisada sem que se temam os conflitos sociais, já que verificar se a investigação respondea um valor ético mais relevante vai além de interesses individuais envolvidos, eédesejável, assim como eticamente sustentável, que se obtenha um conhecimento que ultrapasse 0 senso comum e que favoreça o aprofundamento da dinâmica das relações sociais ${ }^{15}$. Problematizando saberes e práticas em suas intervenções sobre o corpo e a vida individual e coletiva, toma-sea ética como inalienável da produção do conhecimento científico.

Tal perspectiva crítica se configura mais como um potencial do que como um produto observado pela análise destes estudos. Esta relação entre saber e ética ou os possíveis desdobramentos metodológicos desta relação não costumam ser explicitados pelos pesquisadores, mas isto não impede que este tipo de implicação seja levantado. Um desdobramento mais visível se dá quando nos focalizamos sobre a própria descrição dos aspectos metodológicos da pesquisa.

Evidenciou-se que grande parte dos artigos (62) associa o desenho de pesquisa qualitativo quase que exclusivamente ao uso de técnicas que reconhecidamente recolhem dados de cunho qualitativo (depoimentos, percepções, valores, experiências, comportamentos individuais ou grupais), como entrevistas, observações e grupos focais, sejam estas realizadas por meios tradicionais ou diferenciados (como em práticas educativas ou planejamentos estratégicos, por exemplo). Deste total, cerca de dez estudos também se utilizam de fontes documentais e dezoito se nomeiam estudos "quanti-quali".

Outro conjunto de estudos já procura esclarecer procedimentos de análise ou vinculações a métodos mais sistematizados (51), sendo que maioria destes (27) se limita a citar a análise de 
conteúdo (muitas vezes identificada como a proposta por Bardin) ou uma de suas etapas (como a análise temática); também neste grupo de estudos, aparece o recurso a documentos, em poucos casos (5). Os outros 24 estudos deste conjunto explicitam o uso da análise de discurso (11) (associada ou não a diferentes perspectivas, como a hermenêutica dialética ou a fenomenológica, por exemplo); de métodos ou perspectivas etnográficos (9) ou de pesquisa-ação (4).

Embora ainda sujeitas a interpretações, as formas de classificar nossos desenhos de pesquisa, divulgadas nos livros de metodologia, costumam ser tomadas como critérios suficientemente claros para indicar ou não a exigência de cuidados e protocolos éticos. Assim, por exemplo, é comum relacionar pesquisas que se utilizam exclusivamente de dados documentais a uma maior flexibilidade ou a serem dispensadas de certos procedimentos (como o TCLE). Exemplos como o de uso de prontuários para coleta de relatos detalhados e pessoais remete a fragilidades no uso dealgumas classificações genéricas ou da clareza de nossas definições, das quais o caráter de documentos públicos ou não éapenas um exemplo. Q uando a análise se volta para os referenciais teóricos que sustentam a perspectiva analítica dos pesquisadores, mais uma vez se evidencia a implicação ético-política de escolhas aparentemente técnicas. Para embasar uma forte aderência a problemáticas ligadas a demandas críticas sobre as realidades e práticas de saúde em suas contingências histórico-sociais, não é estranho que grande parte dos estudos explicite quadros conceituais que se articulam aos marcos conceituais que abrigam tais interesses, assim como a promoção da saúde, a reforma sanitária e psiquiátrica - algumas vezes denominados como paradigmas ou tomados em marcos legais, princípios ou conceitos específicos, como os de políticas públicas mais ou menos genéricas - o PSF (Programa da Saúde da Família), a municipalização, a intersetorialidade, o trabal ho em saúde, a humanização, a qualidade de vida, a vulnerabilidade, o empowerment e o cuidado, entre outros (48 estudos). Se estes estudos parecem consolidar o lastro do compromisso com a cidadania, também abrem perspectivas para a incorporação de referenciais como o dos direitos humanos, da comunicação social ou da bioética, como bases para pensar 0 conhecimento em saúde ${ }^{12}$.

É evidente que, neste conjunto de explicitações metodológicas, por mais que se permita supor limites de entendimento ao se adotar certos conceitos e referencias como "paradigmas" ou base epistemológica suficiente, não se pode deixar dereconhecer o modo como a saúde coletiva fortalece a relação com as ciências humanas e sociais, sem o que não seria possível delimitar inúmeros objetos. Dito de outro modo, se podemos questionar até que ponto é suficiente assumir um conceito ou uma política como marco teórico, também podemos questionar se, fora de certos modos de pensar e investigar, seria possível tomar a sexualidade, o cuidado, a política ou a mídia, por exemplo, não apenas como um objeto, mas como um acervo complexo de saberes e práticas produzidas socialmentee sobre as quais novas e produtivas implicações com o campo da saúde coletiva podem ser geradas. Se isto pode ser dito destes 59 estudos por este viés agrupados, outros 55 estudos se diferenciam por tornarem mais clara esta filiação a referenciais das ciências humanas e sociais.

Assim, destacam-se neste conjunto pesquisas que adotam a teoria das representações sociai $s^{13}$, o interacionismo simbólico, os modelos de signos edimensões simbólicas do real ${ }^{10}$ e outras tantas interpretações e autores, clássicos e contemporâneos da filosofia, antropologia, sociologia e psicologia (teorias degênero, pós-estruturalismo, fenomenologia, educação, entre outros).

Se este panorama de am plas e diversas traduções e diál ogos interdisciplinares pode ser considerado como terreno frutífero para a qualificação do conhecimento produzido no campo da saúde coletiva, ainda não se pode creditar a tal produtividade resultados conclusivos em termos deamadurecimento econsistência teórica deseus investigadores, especialmente no que se refere à dimensão ética do ofício de pesquisar. Longe de significar uma desqualificação, nossas dúvidas e insuficiências são expressões da historicidade e instabilidades do processo de conhecimento; mostram sim a potencialidade deste movimento.

\section{Consideraçõesfinais}

$\mathrm{N}$ a verdade, o presenteestudo partiu deum limiteinicial econcreto, o da insuficiência deachados reveladores de uma pertinente qualificação ética de pesquisas e pesquisadores. Esta insuficiência pode ser vista como um anúncio de fragilidades da formação/preparo de pesquisadores e do "retrato possível" de nossas publicações, mas esta seria apenas uma interpretação parcial. Assumindo o limite desta interpretação, a opção foi por destacar sim a questão da eticidade das pesquisas qualitativas em saúde como problemática e 
desafiadora. Desafios que incidem diretamente sobre as instituições que assumem a grande parte da tarefa de produzir e formar pesquisadores - o sistema de pós-graduação.

Ao final do estudo, conclui-se que só podemos falar de uma "eticidade" em construção. Os limites apontados por al guns achados ( como são expressos, ou não, os raciocínios éticos que dirigiram pesquisas qualitativas) mostram a dificuldade de levantar questões significativas "nos ditos e não ditos", quando estes ditos estão demarcados por aspectos formais (TCLE e CEP, majoritariamente). Ou seja, não foi intencional a busca por estas formalidades, mas foram elas o grande (eúnico) conteúdo da maioria dos escritos. A escolha por dar destaque ao "não dito", mesmo quando grande parte da análise se prende ao está escrito nos artigos, também destaca uma relativa "invisibilidade" do que real mente está acontecendo e o que estão pensando os pesquisadores sobre este tema. As incertezas produzidas pela leitura dos artigos pesquisados não são suficientes para afirmar sobre a qualificação ética de nossas pesquisas e, portanto, parece que o limite inicial permanece como desafio presente.

Já é apontado que a consolidação do Sistema CEP/CONEP, o avanço na incorporação das questões de ética em pesquisa à esfera política e o controlesocial da prática científica têm sido acompanhados apenas de forma tímida pelo processo de formação acadêmica de jovens pesquisadores $^{16}$. I sso parece causar um descompasso entrea lógica avaliativa das pesquisas e a capacitação ética dos investigadores para promoverem uma cultura de direitos humanos e para fazerem da equidade parte integrante de seu cotidiano. Essa situação toma dimensão de desafio quando se considera o número expressivo decursos de pósgraduação em nível de mestrado e doutorado, atualmente credenciados pela Coordenação de Aperfeiçoamento de Pessoal de Nível Superior (CAPES) e, por consequência, o também elevado número de pesquisas científicas com seres humanos em andamento ${ }^{16}$.

Portanto, essa missão que se apresenta à comunidade acadêmica se traduz na necessi dade de aprofundar, de forma crítica, as reflexões éticas sobre os problemas morais presentes nas pesquisas qual itativas em saúde (e nas pesquisas em ciências humanas e sociais de uma forma geral), contrastando com a postura que assume que a eticidade de uma pesquisa está relacionada apenas com sua cientificidade ou que confunde justiça com o simples cumprimento de dispositivos legais ${ }^{17}$.
A adoção de princípios éticos na prática de pesquisa, representados por diretrizes internacionais e por regulamentação nacional, é apenas 0 passo inicial para a proteção dos participantes dos estudos. 0 processo de formação dos novos pesquisadores tem papel fundamental no desenvolvimento de sua capacidade de realizar julgamentos morais e de agir em conformidade com eles, provocando conflitos cognitivos e o raciocínio crítico, numa crescente sensibilização para a importância da consolidação da equidadena realização das pesquisas respeitando as pessoas envolvidas ${ }^{17}$.

Finalmente, cabe lembrar que não são poucos ou simples os motivos que têm trazido à baila o tema da ética na pesquisa em saúde. Cada uma dessas motivações pode e deve levar a estudos mais minuciosos ededicados a anal isar especificidades que se referem aos próprios desenhos de pesquisa (como em tipos peculiares de estudos com ou sem intervenção) ${ }^{13}$; aos interesses equestõeseconômico-sociais envolvidas; as políticas de ciência e tecnologia com suas agendas, prioridadeseformas definanciamento; aos dilemaséticos potenciais ou reais (negligenciados ou não); às diretrizes e regulamentações em seus cenários políticos nacionais e internacionais; às populações e sujeitos pesquisados em seus direitos eformas deproteção; à relação entreética erigor científico; ao comportamento e preparo do pesquisador nas decisões aparentemente e equivocadamente tomadas como exclusivamente técnicas e isentas de julgamento moral, entre outros.

M esmo tendo o objetivo de analisar o tema da "eticidade" em pesquisa qual itativa em saúde, o estudo não pretendeu abarcar a complexidade evariedade dequestões no interior destetema. A opção por levantar indicativos que emergem de um dos produtos da própria atividade investigativa (artigos) já implica alguns limites, mas também em clara el eição por dar relevânciaa pistas práticas deste cotidiano de "pesquisar e publicar" em que jovens e experientes pesquisadores compartilham dúvidas, conflitos e contingências diversas.

Partimos da premissa que ainda há muito a ser problematizado acerca deste cotidiano da pesquisa equeisso exige explicitação, exposição e abertura à crítica. Precisamos conhecer o quefalamos e o que fazemos em nome da ética em nossas pesquisas. Ou ainda, precisamos pensar sobre 0 que não dizemos e o que não fazemos quando nos sentimos amparados e resguardados por já estar dizendo o mínimo exigido, o protocolar, o silêncio quesucedeà mera obediên- 
cia à norma. Em ética, basta a obediência e 0 protocolar? Por mais que possamos considerar os avanços promovidos por meio de nossas re gulamentações, isso deve implicar a suspensão de qualquer autocrítica? Estamos tão seguros assim em nossas atuais posições? Só evidenciamos os efeitos positivos deste processo deampliação do interesse pela ética em pesquisa?

Suspender o excesso de confiança, talvez até desconfiar ou retornar ao terreno em quea insegurança e o desconforto não são tão maus assim, pode ser uma atitude ética interessante. Quando a lei máxima e mais corriqueira, quase inquestionável, épublicar epublicar sempre, mais e mais, é fundamental que se volte à atenção sobre do que se abre mão, o que se perde sob esta máxima. Talvez se tenha que voltar a definir o que é um autor ou co-autor (isto se perdeu?) e admitir outras tantas coisas não ditas, mas tão questionáveis ou perturbadoras no cotidiano da pesquisa quanto às recrimináveisfalhas quetoda a vigilânciaética quer evitar.

\section{Colaboradores}

FRS Ramos trabalhou na concepção teórica da pesquisa e na redação do texto, M Finkler e ER Gonçalves trabalharam na coleta de dados e na redação do artigo e JC Caetano colaborou com a revisão final do texto. 


\section{Referências}

1. Ramos FRS. Trabalho e Educação - Ética/Bioética na experiência de si do trabalhador da saúde [relatório de pesquisa]. Lisboa: Faculdade de Psicologia e Ciências da Educação, Universidade de Lisboa; 2006.

2. Foucalt M. A ordem do discurso. 3a ed. São Paulo: Loyola; 2006.

3. Hacking I. A múltipla personalidade e as ciências da memória. São Paulo: José Olympio; 2000.

4. Schramm FR. A moralidade da prática de pesquisa nas ciências sociais: aspectos epistemológicos e bioéticos. Cien Saude Colet 2004; 9(3):773-784.

5. Brasil. Ministério da Saúde. Conselho Nacional de Saúde. Resolução 196 de 10 de outubro de 1996. Estabelece as diretrizes e normas regulamentadoras de pesquisas envolvendo seres humanos. Diário Oficial da União 1996; 16 out.

6. Freitas C, Lobo M, Hossne W. Sistema CEP-CONEP: 9 anos (1996 a 2005). 2006 [site da Internet] [acessado 2007 mar 13]. Disponível em: http://conselho. saude.gov.br/comissao/conep/relatorio.doc

7. Brasil. Ministério da Saúde. Conselho Nacional de Saúde. Comitê Nacional de Ética em Pesquisa. Relação de todos os CEPs. 2006 [site da Internet] [acessado 2007 mar 13]. Disponível em: http://conselho. saude.gov.br/comissao/conep/2006/cepsapravados. doc

8. Santos BRL, Eidt OR, Gerhardt LM. Os Comitês de Ética em Pesquisa: a transição paradigmática na pesquisa em busca da dignidades dos seres humanos. In: Mancia JR, Vargas MA, organizadores. Livro-temas da 66a Semana Brasileira de Enfermagem: A Bioética e os modos de ser da Enfermagem. Brasília: Associação Brasileira de Enfermagem; 2005. p. 33-38.

9. Lunardi VL, Filho WDL, Silveira RS, Pelzer $M T$, $M$ ancia JR. A ética na pesquisa e os comitês de ética em pesquisa. In: M ancia JR, Vargas MA, organizadores. Livro-temas da 66a Semana Brasileira de Enfermagem: A Bioética e os modos de ser da Enfermagem. Brasília: Associação Brasileira de Enfermagem; 2005. p. 75-80.
10. Batistiolle JV, Silva Júnior WJ. Comitês de ética em pesquisa e a vulnerabilidade dos sujeitos de pesquisa: um relato de experiência. 0 M undo da Saúde 2006; 30(3):465-470.

11. Foucalt M. O cuidado com a verdade. In: Foucalt M. Ética, sexualidade, política. Rio de Janeiro: Forense Universitária; 2004.

12. Medeiros M, M unari DB, Bezerra ALQ, Barbosa MA. Pesquisa qualitativa em saúde: implicações éticas. In: Guilhem D, Zicker F, organizadores. Ética na pesquisa em saúde: avanços e desafios. Brasília: Letras Livres/UnB; 2007. p. 99-118.

13. Machado LN. Ética em pesquisa biomédica e antropológica: semelhanças, contradições, complementaridade. In: Guilhem D, Zicker F, organizadores. Ética na pesquisa em saúde: avanços e desafios. Braślia: Letras Livres/UnB; 2007. p. 119-142.

14. Ramos FRS, Padilha MICS, Borenstein MS, Martins CR. A responsabilidade do pesquisador ou sobre 0 que dizemos acerca da ética em pesquisa. Texto Contexto Enferm 2005; 14(1):96-105.

15. Guerreiro ICZ. Aspectos éticos das pesquisas qualitativas em saúde [tese]. São Paulo (SP): Universidade de São Paulo; 2006.

16. Guilhem D, Zicker F. Introdução. In: Guilhem D, Zicker $F$, organizadores. Ética na pesquisa em saúde: avanços e desafios. Brasília: Letras e Livros/UnB; 2007. p. 13-28.

17. Rego S. Prefácio. In: Guilhem D, Zicker F, organizadores. Ética na pesquisa em saúde: avanços e desafios. Braślia: Letras e Livros/UnB; 2006. p. 10-12.

Artigo apresentado em 27/07/2007

A provado em 20/12/2007 